\title{
GLOBALIZAÇÃO E CRISE DO ESTADO NACIONAL
}

\author{
Maria Cecília Spina Forjaz \\ Visiting Fellow na Universidade de Yale, Visiting Professor na \\ Universidade de Massachusetts, Phillips Professor na University of \\ Texas at Austin e Professora do Departamento de Fundamentos \\ Sociais e Jurídicos da Administração da EAESP/FGV. \\ E-mail: mforjaz@fgvsp.br
}

\section{RESUMO}

A pesquisa analisa a crise do Estado Nacional no contexto da ordem mundial pós-Guerra Fria, enfatizando o fortalecimento de instâncias de poder supranacionais e infranacionais que estão solapando a autonomia dos Estados. Tais transformações na esfera política estão vinculadas ao processo geral de globalização.

\section{ABSTRACT}

The research studies the National State crisis in the context of the post-Cold War world. The research points out that this crisis is mainly related to the strength of new global institutions and the emergency of subnational organizations, both weakening the National State power and sovereignty. These changes are linked to the globalization process.

\author{
PALAVRAS-CHAVE \\ Estado Nacional, ordem mundial, Guerra Fria, globalização.
}

KEY WORDS

National State, global order, Cold War, globalization. 


\section{INTRODUÇÃO}

O fenômeno mais importante e abrangente da atualidade e sobre o qual muito se tem escrito e debatido - a globalização envolve inúmeras dimensões, das quais citamos as mais conhecidas: econômica, financeira, tecnológica, ecológica, cultural, política, bem como a revolução no mundo das comunicações. Desses diferentes aspectos, os mais reconhecidos e visíveis são as alterações econômico-financeiras, não por acaso a temática predominante nos estudos sobre a globalização.

A freqüência e o volume da produção intelectual sobre esse tema, no entanto, não significam que haja unanimidade ou convergência de pontos de vista. Pelo contrário, a polêmica é intensa, e determinadas correntes de pensamento, em geral situadas à esquerda no espectro ideológico, consideram haver mais mito do que realidade nas constatações referentes ao processo de globalização.

Anthony Giddens considera que as divergências relativas ao conceito de globalização referem-se fundamentalmente ao conflito ideológico/político entre neoliberais e social-democratas ou socialistas ou, em última instância, ao conflito entre direita e esquerda como ele se manifesta atualmente.

Se existe polêmica a respeito dos aspectos mais conhecidos da globalização, o que não dizer da dimensão política, que mereceu menos atenção, até o momento, das ciências sociais? Nosso estudo está situado nessa área do conhecimento e refere-se a uma temática relevante, mas ainda pouco desenvolvida, da Ciência Política.

Embora a pesquisa sobre os aspectos políticos da globalização esteja nos seus estágios iniciais, existe unanimidade na avaliação de que o Estado Nacional tem enfrentado grave crise a partir da década de 70. Analisar em profundidade as características dessa crise é um dos problemas deste artigo.

A recente crise global das bolsas de valores abarcando todos os continentes e espalhando o pânico nos países desenvolvidos, assim como nos chamados "mercados emergentes", atualiza, de forma extremamente concreta, a urgência de ampliar o conhecimento sobre o fenômeno da globalização em todos os seus aspectos. Diferentemente do crash de 1987, que não produziu uma reação em cadeia tão ampliada, agora, de fato, a crise ameaça os mais variados países, apesar de suas origens no sudeste asiático.
Estado Nacional, embora tenha entrado num longo processo de transformações vinculadas à globalização, ainda é um ator fundamental na economia mundial e apenas começa a sofrer limitações em sua soberania e em sua autonomia decisória.
Pela primeira vez, a turbulência financeira iniciada em economias emergentes propagou-se para as potências do G7 e colocou na agenda internacional a urgência de criar mecanismos de regulação internacional para impedir novas crises. Tais questões estão todas vinculadas de forma bastante estreita à temática dos limites da autonomia de gestão dos Estados Nacionais discutida no artigo.

Além da importância do tema, este estudo busca possibilitar o desenvolvimento de uma reflexão crucial dentro da Ciência Política, que está relativamente "atrasada", na medida em que o próprio objeto da pesquisa, a globalização política, está menos avançado do que a globalização econômica, financeira e tecnológica.

$\mathrm{O}$ avanço dos fatos políticos em relação à interpretação teórica deles é bem observado por Leo Panitch (1994, p. 16): "É preciso dizer que muitas contribuições para a compreensão do papel do Estado dentro do processo contemporâneo de globalização ficaram atrás do próprio processo [grifo nosso], e no geral permaneceram um pouco estreitas, pelo menos em comparação com duas contribuições chaves sobre o assunto feitas duas décadas atrás."

O caráter recente da crise do Estado Nacional implica a inexistência de um corpo consolidado de conhecimentos e a oportunidade para o pesquisador de inovar, aprofundar e debater idéias bastante novas, assim como comparar interpretações extremamente conflitantes.

Para introduzir o tema, é importante mostrar a profundidade da divergência tanto sobre a temática mais geral - globalização - quanto sobre 
um de seus aspectos - a crise do Estado Nacional. Alguns autores têm uma visão extremada sobre o fenômeno da globalização, tanto na dimensão econômica quanto na política.

No aspecto político, visão extremada quer dizer uma consideração exagerada sobre a crise de poder, soberania e autonomia decisória dos Estados Nacionais. Na perspectiva desses autores (que, em geral, não são cientistas políticos), o Estado perdeu totalmente a importância como agência decisória, tendo sucumbido diante da força poderosa do mercado globalizado e dos fluxos financeiros que não respeitam as fronteiras nacionais.

Essa visão extremada está principalmente nos círculos políticos, nas organizações multilaterais e no mundo dos negócios, tendo, portanto, alta capacidade de fazer barulho e amplificar sua versão radical sobre a globalização do mundo, influenciando, assim, a opinião pública em geral.

Citamos um exemplo típico de versão radical na pessoa de Kenichi Ohmae (1996, p. 5), ex-diretor da empresa de consultoria McKinsey \& Company, que diz o seguinte em um de seus últimos livros: "Pelo contrário, o que estamos testemunhando é o efeito cumulativo de mudanças fundamentais nas correntes da atividade econômica ao redor do globo. Essas correntes se tornaram tão poderosas que abriram canais inteiramente novos para si próprias - canais que nada devem às linhas de demarcação dos mapas políticos tradicionais. Simplesmente, em termos dos fluxos reais de atividade econômica, os EstadosNações já perderam seus papéis como unidades significativas de participação na economia global do atual mundo sem fronteiras."

Existe outra visão, outra versão, mais moderada, a respeito da mundialização que estamos vivendo na atualidade e que predomina nos meios acadêmicos, tanto entre economistas como em outras especialidades de cientistas sociais. Reproduzimos aqui uma citação de representantes típicos dessa visão moderada: "Algumas análises menos extremadas e mais matizadas que empregam o termo 'globalização' são bem estabelecidas na comunidade acadêmica e concentram-se na internacionalização relativa dos principais mercados financeiros, da tecnologia e de alguns importantes setores da indústria e dos serviços, particularmente desde a década de 70 . Muitas dessas análises enfatizam as restrições crescentes à governabilidade de nível nacional, que impede políticas macroeconômicas ambiciosas significativamente divergentes das normas aceitáveis pelos mercados financeiros internacionais" (Hirst e Thompson, 1998, p. 17).

Dissemos que a versão moderada predomina nas universidades e nos centros de pesquisa, o que não quer dizer que esteja ausente entre políticos, burocratas, consultores empresariais e executivos, assim como a visão extremada (ou radical) também está presente na obra e na cabeça dos acadêmicos.

Existe uma terceira perspectiva teórica, predominante nos setores intelectuais ou entre políticos de esquerda, que nega totalmente o fenômeno da globalização, considerando-o uma "moda intelectual passageira", sem nenhuma consistência teórica e sem nenhum respaldo efetivo em dados empíricos. Um dos porta-vozes dessa terceira posição é o economista Paulo Nogueira Batista Júnior, que costuma apontar o exagero e a mistificação, tanto no alcance quanto na novidade dos processos de expansão da economia internacional neste fim de século.

Obviamente, não estamos atribuindo a todos, nem mesmo à maioria dos pensadores de esquerda, essa postura de recusar a globalização e a extinção do Estado Nacional, como podemos perceber na obra de Immanuel Wallerstein (1988, p. 14), que, embora reconhecendo uma economia-mundo capitalista, não elimina a importância do Estado Nacional: "a superestrutura da economia-mundo capitalista é um sistema de Estados interdependentes, sistema esse no qual as estruturas políticas denominadas 'Estados soberanos' são legitimadas e delimitadas. Longe de significar total autonomia decisória, o termo 'soberania' na realidade implica uma autonomia formal, combinada com limitações reais desta autonomia, que é implementada simultaneamente pelas regras explícitas e implícitas do sistema de Estados interdependentes e pelo poder de outros Estados do sistema."

Diante da polêmica rapidamente explicitada acima, assumimos a visão moderada, tanto do ponto de vista econômico quanto do político, e julgamos que nosso principal objeto de estudo, o Estado Nacional, embora tenha entrado num longo processo de transformações vinculadas à globalização, em todos os seus aspectos, ainda é um ator fundamental na economia mundial e apenas começa a sofrer limitações em sua soberania e em sua autonomia decisória, fenômenos que pretendemos analisar a seguir. 
O artigo está estruturado em duas partes principais. Na primeira delas, "Formação e declínio do Estado Nacional", vamos buscar as convergências analíticas na descrição desses processos históricos, com maior ênfase no declínio iniciado com a globalização.

$\mathrm{Na}$ segunda parte, passamos a expor a visão divergente de três pensadores importantes da atualidade a respeito da crise do Estado, Peter Drucker, consultor empresarial, Eric Hobsbawm, historiador, e Samuel P. Huntington, cientista político, que têm visões bem diferentes a respeito da crise do Estado Nacional.

As diferenças se relacionam:

a) às diversas áreas do conhecimento a que eles se dedicam;

b) a posições divergentes no espectro ideológico contemporâneo: Drucker e Hobsbawm podem ser considerados antípodas, representando o neoliberalismo e o marxismo, respectivamente. Quanto à Huntington, renomado cientista político americano, leciona na Universidade de Harvard, onde também dirige o Instituto para Estudos Estratégicos John M. Olin. Foi assessor do presidente Carter na área de Segurança Nacional e sua obra mais recente, $O$ choque de civilizações e a recomposição da ordem mundial (Huntington, 1997), será comentada mais adiante. Tem uma postura "democrático-progressista", considerando-se o espectro ideológico próprio dos Estados Unidos, e representa os interesses da maior potência da atualidade.

c) ao foco de análise: enquanto Drucker e Hobsbawm estão mais centrados na questão da crise do Estado Nacional perante as forças da globalização, Huntington, no livro citado anteriormente, trata das relações entre os Estados Nacionais num mundo definido pelo conflito entre civilizações, unidade de análise mais abrangente e que incorpora diversos Estados Nacionais. Apesar dos focos distintos, Huntington também reconhece a crise do Estado e tem algumas convergências a esse respeito com Drucker e Hobsbawm. Interessante é observar que todos os autores citados, sejam quais forem suas perspectivas teóricas a respeito da atual crise do Estado Nacional, têm um ponto em comum: a periodização que localiza na década de 70 o início dessa crise. A sequiência do texto tornará claras as razões dessa unanimidade.

\section{FORMAÇÃO E DECLÍNIO DO ESTADO NACIONAL}

A formação do Estado Nacional constituiu um longo processo histórico entre os séculos VIII e XIV na Europa Ocidental, durante o feudalismo, e envolveu a construção paulatina de uma autoridade central e soberana que foi aos poucos submetendo entidades de poder subnacionais, o feudo e a cidade (ou burgo), assim como entidades de poder supranacionais, isto é, a Igreja Católica e o
Ao lado das organizações multilaterais, os blocos regionais também são entidades supranacionais mais abrangentes que - Estado e que vão, cada vez mais, destacando grupos de nações.
Santo Império Romano Germânico, que representou a união da cristandade ocidental e se espraiou desde a Alemanha até a Espanha, incluindo todos os atuais países da Europa Ocidental.

A autoridade central do soberano aos poucos se impôs e sobrepujou os particularismos locais, assim como os poderes amplos do Papa e do Imperador, ou seja, o poder real tornou-se mais abrangente do que o dos senhores feudais e o da burguesia das cidades e suplantou também aqueles poderes de âmbito mais extenso do que o nacional. Em torno do poder real fortalecido sobre um território definido, a identidade política dos cidadãos passou a ser definida como identidade nacional.

Foram os seguintes os processos mais significativos na constituição do Estado Nacional:

a) a crescente coincidência entre fronteiras territoriais e um sistema uniforme de leis;

b) a criação de novos mecanismos de elaboração e imposição de leis;

c) a centralização do poder administrativo;

d) o estabelecimento de impostos e de gestão do sistema fiscal;

e) a criação de Forças Armadas nacionais;

f) a constituição da diplomacia para regular as relações entre Estados Nacionais.

A elaboração teórica da idéia de Estado Nacional recebeu grande ímpeto a partir do século 
$\mathrm{XVI}$, quando a Reforma e as guerras religiosas opuseram várias nações entre si e terminaram definitivamente com a unidade religiosa do Ocidente. Os primeiros teóricos importantes acerca do Estado foram Jean Bodin e Thomas Hobbes, e ambos tratam da noção central de soberania do Estado, isto é, das condições para o exercício legítimo da autoridade sobre um território e uma população.

A idéia de soberania do Estado evoluiu posteriormente para a de soberania popular no pensamento de Locke e Rousseau, que, pela primeira vez, desenvolvem a noção de que a fonte e a origem do poder político devem ser o consentimento dos cidadãos. A partir daí, surgem as teorias da democracia, que foram sofisticando cada vez mais a idéia de que a origem da soberania é a vontade popular ou "vontade geral", na expressão de Rousseau.

Até o século XX, a soberania estatal continuava sendo considerada como órgão único de poder, independentemente de ser baseada no consentimento popular ou no arbítrio dos governantes, e o Estado Nacional continuava sendo o principal ator no cenário internacional e um dos principais conceitos da Ciência Política: "A teoria política e a lei constitucional ainda conhecem somente o Estado soberano. E nos últimos duzentos anos esse Estado tem ficado cada vez mais poderoso e dominante, transformando-se num 'megaestado' (...). Cada um dos quase 200 países que surgiram dos antigos impérios coloniais desde o fim da Segunda Guerra Mundial foi estabelecido como Nação-Estado soberana. E é isso que aspira se tornar cada uma das partes do último império colonial, o Império Soviético" (Drucker, 1993, p. XVIII).

Com a globalização, no fim do século $X X$, novamente o Estado Nacional passa a sofrer a competição de instituições supranacionais ou transnacionais e subnacionais ou infranacionais de poder, assim como na Idade Média, configurando um processo histórico que alguns autores têm denominado de Novo Medievalismo ${ }^{1}$.

Vejamos, em primeiro lugar, as instituições de âmbito maior, mais amplo do que o Estado Nacional, e que passam a constituir uma nova soberania externa, um novo poder que constrange por fora e limita o Estado de forma semelhante à Igreja e ao Império durante o feudalismo.

São organizações ou instituições externas que passam a exercer funções governamentais ou formular regulamentos e leis que se impõem aos Es- tados, anteriormente absolutamente imunes a qualquer instância de poder superior a si próprios.

As organizações multilaterais, como a Organização das Nações Unidas e a Organização Mundial do Comércio, o Fundo Monetário Internacional e o Banco de Compensações Internacionais, entre outras, estão crescentemente se fortalecendo e impondo restrições ao poder outrora absoluto dos Estados Nacionais.

$\mathrm{O}$ fato de que alguns Estados Nacionais hegemônicos tenham grande influência sobre essas organizações implica grandes assimetrias no efetivo poder de diferentes Estados Nacionais, mas não elimina o fato novo de que todos os Estados Nacionais estão hoje sujeitos a poderes mais amplos do que eles próprios, ou seja, mesmo que apenas os países que participam do conselho permanente do Conselho de Segurança da ONU tenham poder de veto sobre as suas resoluções, isso não elimina o fato de que esses países também estão submetidos ao poder do Conselho de Segurança de uma organização que é supranacional. Muitos outros exemplos poderiam ser lembrados para mostrar como passou a existir uma dupla soberania, ou soberanias superpostas, ou mesmo diferentes níveis de soberania (externa e internamente) que exercem constrangimentos e limitações sobre o antigo poder absoluto e indivisível das Nações-Estado.

Tanto os Estados Unidos quanto a Nigéria têm que aceitar as regras de comércio internacional estabelecidas no âmbito da OMC, não importando o diferencial de poder e riqueza que os caracteriza, a despeito da imensamente maior influência americana no momento da formulação dessas regras. Entretanto, uma vez aceitas pela $\mathrm{OMC}$, as regras passam a se impor igualmente a ambas as nações.

Ao lado das organizações multilaterais, os blocos regionais também são entidades supranacionais mais abrangentes que o Estado e que vão, cada vez mais, destacando grupos de nações. Embora tenham diferentes graus de integração, a constituição desses blocos é uma tendência inequívoca da atualidade. Exemplificando mais uma vez a noção da superposição de soberanias, lembramos a situação da França, submetida simultaneamente à ONU e à União Européia.

As empresas transnacionais são entidades que transcendem as fronteiras dos Estados Nacionais e sua lógica de operação e suas estratégias não estão condicionadas por razões de Estado, mas sim pela busca de mercados atraen- 
tes e melhores condições de investimento, estejam elas onde estiverem.

O fluxo contínuo do capital financeiro igualmente não respeita as fronteiras nacionais, e os Estados não têm mais condições de controlá-lo, assim como a rede global das comunicações está acima das possibilidades de gestão local.

A informação e o dinheiro não têm pátria, assim como outras necessidades atuais exigem instituições globalizadas: é o caso das políticas de proteção ambiental que não podem se ater às fronteiras nacionais e exigem atuação em escala mundial.

Se os neoliberais tendem a exagerar a perda de poder e autonomia que os Estados Nacionais vêm sofrendo, a esquerda tem muita dificuldade em aceitar e reconhecer a diminuição das funções estatais: "Toda tentativa de reavaliar as estratégias da esquerda no contexto da globalização deve começar com o entendimento de que apesar de que a natureza da intervenção estatal mudou consideravelmente, o papel do Estado não foi necessariamente diminuído. Longe de estar testemunhando a ultrapassagem do Estado por um capitalismo global, o que nós vemos são Estados muito ativos e grupos de classes capitalistas altamente politizadas trabalhando arduamente para assegurar o que Stephen Gill (...) chamou de 'um novo constitucionalismo para disciplinar o neo-liberalismo"” (Panitch, 1994, p. 14).

Se a esquerda tem tido dificuldades em reconhecer as restrições dos Estados Nacionais perante as forças supranacionais, desde os anos 70, o pensamento de esquerda vem postulando e tentando analisar o fenômeno da internacionalização do Estado. Num artigo importante publicado na New Left Review em 1971, Robin Murray (1971, p. 84-108) se questionava sobre os efeitos da internacionalização do capital nas instituições políticas existentes.

Alguns anos depois, Nikos Poulantzas tentou interpretar a internacionalização do Estado e a hegemonia americana no mundo capitalista no livro Classes no capitalismo contemporâneo, publicado em 1974. Nessa obra, o autor recusa a supressão ou ultrapassagem da Nação-Estado, mas reconhece profundas alterações advindas da interpenetração do capital transnacional com as burguesias domésticas.
Em 1987, Robert Cox publicou Produção, poder e ordem mundial, livro que avançou muito na análise das transformações do Estado diante da globalização na perspectiva da esquerda. Sem abdicar das tradicionais funções atribuídas ao Estado nas sociedades capitalistas, o autor situa o início do processo de inter- nacionalização do Estado no pós-1945, com a imposição da Pax Americana. Segundo o autor, esse processo implica:

a) a formação de um consenso entre Estados relativo às necessidades da economia mundial dentro dos parâmetros de uma ideologia comum (acordos de Bretton Woods);

b) a participação hierarquicamente estruturada nesse consenso;

c) o ajustamento das estruturas internas dos Estados para transformar o consenso global em política nacional.

Essas mudanças não significaram um Estado menos poderoso, mas uma reestruturação na hierarquia dos aparatos de Estado, na qual certas agências nacionais (banco central, alta burocracia econômica, diplomacia) se tornaram instrumentos de transmissão das agências centrais da economia mundial.

Um novo estágio na internacionalização teria ocorrido no pós-crise 1968-1975, com o aprofundamento da globalização e a diminuição da hegemonia americana. Nessa época, impõe-se a doutrina que Cox chama de forma de Estado hiperliberal Thatcher-Reagan. Agora ele se tornou um cinto de transmissão entre a economia global e a economia nacional. Seria o "Estado mínimo", expressão mais consolidada na literatura, que não cria nenhum tipo de embaraço às forças do mercado. 
O texto exposto demonstra uma progressiva aceitação pela esquerda das alterações no Estado promovidas pelas forças supranacionais engendradas pela globalização capitalista, mas também evidencia que, durante um tempo considerável, a esquerda se recusou a aceitar que a crise do Estado keynesiano e do Welfare State era uma crise estrutural do capitalismo avançado.

Mais recentemente, autores e instituições que não são de esquerda vêm revendo as concepções neoliberais sobre o Estado mínimo e notando uma nova percepção sobre as funções do Estado no mundo globalizado.

Exemplo importante dessa nova tendência são as observações do relatório do Banco Mundial publicado em 1997 (The State in a changing world): "Estas mudanças têm significados novos e diferentes papéis para os governos - não mais como provedores, mas como facilitadores e reguladores (...). O desenvolvimento econômico e social sustentável é impossível sem um Estado atuante. Tem-se tornado crescentemente consensual a idéia de que um Estado atuante - e não um Estado mínimo - é central ao desenvolvimento econômico e social, ainda que como parceiro e facilitador do que como um diretor."

Na década de 90, predominou a discussão sobre o "fim do Welfare State", mas artigo recente publicado pela revista The Economist contradiz essa noção: "A descoberta interessante do estudo é que, em todas as economias avançadas, os gastos do governo têm crescido, e rapidamente, como porcentagens do PNB. Nos países desenvolvidos, sua média manteve-se em vigorosa ascensão: $27,9 \%$ (1960), 42,6\% (1980), 44,8\% (1990) e 45,9\% (1996). Dentre esses países os Estados Unidos e o Japão têm as menores proporções de gastos de governo com relação ao seu PNB (33\% e 36\%, respectivamente, em 1996). Portanto, em plena era da 'globalização' e do discurso neoliberal sobre o Estado, a participação dos gastos do governo no produto nacional continua a aumentar" (Dupas, 1998, p. 55-6).

A autoridade dos Estados Nacionais também está sendo solapada por dentro, por entidades subnacionais e forças centrífugas como o tribalismo e o fortalecimento dos níveis de poder infranacional como municípios ou províncias, cada vez mais autônomos e poderosos. Vamos analisar por partes essas forças internas, que, a partir de dentro, corroem a capacidade de coesão e integração dos Estados Nacionais.
As "tribos" ou "grupos de identidade" são novos grupos sociais definidos por etnia, religião, gênero, cultura e até mesmo idioma, cuja lealdade e identidade abrangem menos que o Estado Nacional e dentro dele pressionam por autonomia e aspiram, freqüentemente, a constituir um novo, menor e mais inclusivo Estado Nacional. Exemplo clássico dessa situação é o Canadá ou mesmo a Espanha dos bascos e catalães.

Aqui estamos nos referindo a um dos paradoxos da contemporaneidade: o Estado Nacional em crise engendra a multiplicação de Estados Nacionais em geral menores e mais unitários em termos culturais, ou seja, ao mesmo tempo em que os Estados Nacionais estão declinando e se modificando, estão surgindo novos Estados.

No entanto, nem sempre os grupos de identidade aspiram à constituição de novas nações, como bem relata Hobsbawm (1995, p. 417-18): "O que a política de identidade étnica teve em comum com o nacionalismo étnico fin-de-siècle foi a insistência em que a identidade de grupo da pessoa consistia numa característica existencial, supostamente primordial, imutável e portanto permanente, partilhada com outros membros do grupo e com mais ninguém. (...) À medida que o século chegava ao fim, a ausência de instituições e mecanismos de fato capazes de lidar com esses problemas se tornava cada vez mais evidente. O Estado-Nação não era mais capaz de lidar com eles, quem ou o quê, seria?"

Outro autor que faz observações bastante interessantes sobre as transformações na identidade nacional é Roland Axtmann (1997, p. 14041), em livro recentemente publicado na Inglaterra e Estados Unidos: "o revivalismo étnico e o nacionalismo assim como o fundamentalismo religioso podem ser entendidos do ponto de vista do analista como um aspecto necessário da globalização. Do ponto de vista dos participantes, eles podem aparecer como uma resposta adequada ao que pode ser visto como uma ameaça homogeneizadora da globalização, e então como uma reafirmação ou reinvenção de uma identidade coletiva particularista. Em vários países não Ocidentais estamos testemunhando o jogo de tensões dialéticas entre 'modernização' e 'indigenização' cultural; entre o 'universal' e o 'particular'; entre o 'global' e o 'local'; em resumo, a dialética entre homogeneidade e heterogeneidade."

Ser cidadão de um Estado Nacional está deixando de ser o principal critério definidor da 
identidade sociopolítica, e surgem simultaneamente outros critérios mais inclusivos para delimitar a participação em comunidades menores. Ou melhor, surgem diferentes graus ou níveis de definição de identidades sociais, formando círculos concêntricos de inclusão e exclusão alojados no planeta Terra, que passa a ser o círculo mais abrangente ao qual nos referimos e não mais a pátria, como nos séculos XIX e XX, porque já estamos no século XXI, segundo Hobsbawm. Agora estaríamos efetivamente começando a realizar nosso destino como cidadãos do mundo e ao mesmo tempo como participantes de comunas ou corporações locais, e o nível intermediário, o Estado Nacional, vai perdendo relevância e nitidez como definidor de identidade social, cultural e política.

No entanto, além da desintegração nacional promovida pelo tribalismo, os Estados Nacionais vêm sofrendo processos de descentralização política derivados do enorme fortalecimento dos níveis subnacionais de poder como municípios ou províncias. Crescentemente, as políticas públicas que afetam diretamente a vida dos cidadãos são definidas no nível local, e não mais no nível nacional.

Alguns cientistas políticos opõem ao conceito de globalização o conceito de localização, referindo-se a esse fenômeno de descentralização político-administrativa que afeta os Estados contemporâneos. A localização seria exatamente um dos desdobramentos políticos da globalização, uma das conseqüências dela, e não uma força contrária ou contraditória. Exatamente porque estão se esfacelando as estruturas políticas nacionais e as identidades construídas em nível nacional, os cidadãos precisam pertencer a comunidades menores que lhes dêem raízes, que os façam sentir participando de um universo comum.

A contrapartida da mundialização que destrói fronteiras e interconecta regiões antigamente separadas e distantes, bem como as novas noções de tempo e espaço que desenraízam os habitantes das nações, tornando-os habitantes do planeta Terra, é o mesmo fenômeno que produz a necessidade da localização: "Enfim, num mundo urbanizado, em que tudo está interconectado, não há razão para que o essencial dos problemas do nosso cotidiano, a escola, a saúde, a pequena produção etc., não sejam regulados diretamente pelos interessados, a população, através das instâncias locais. Assim é o conjunto do espaço de regulação que está sendo reordenado, exigindo uma revisão em profundidade da articulação dos diversos níveis" (Dowbor, 1996, p. 12-3).

Seja internamente, seja externamente, os Estados Nacionais vêm sendo pressionados pelas forças da globalização, reproduzindo com os si- 
nido a conceitualização de humanidade através do desenvolvimento da noção legal de 'herança comum da humanidade' (...). Se nós aceitamos o argumento dos direitos humanos então a violação desses direitos por um Estado pode servir como fundamento para que uma organização internacional como as Nações Unidas ou uma coalizão de Estados poderia intervir naquele Estado para assegurar que os direitos humanos sejam respeitados ou reestabelecidos."

O pedido de extradição do General Augusto Pinochet feito pela Espanha e outros países europeus em outubro de 1998 para julgá-lo por desrespeito aos direitos humanos durante o regime militar chileno liga-se a essa questão da legislação supranacional. A imunidade do General (estabelecida pelo Estado Nacional chileno) é maior do que o desrespeito à legislação global que protege os direitos humanos? Pode uma lei internacional se impor à legislação interna de um Estado Nacional? De acordo com o advogado espanhol Juan Garcés, que representa 4 mil vítimas do regime Pinochet, o caso contra o General é baseado em princípios legais internacionais e não há imunidade "nacional" que se sobreponha a crimes contra a humanidade.

b) a internacionalização do processo de tomada de decisões: criação de um sistema de governança mundial por meio das organizações multilaterais já citadas.

c) a criação de estruturas internacionais de segurança: a proliferação de armas de destruição em massa tem estimulado a constituição de estruturas internacionalizadas de controle e promoção da segurança coletiva. Nenhum Estado Nacional isoladamente, por mais poderoso que seja, tem condições de promover a segurança global. A recente Guerra do Golfo é um bom exemplo disso.

d) a globalização cultural: a moderna tecnologia da informação e das comunicações cria maiores vínculos entre nações e regiões, o que não significa, para Held (1995, p. 125), a criação de uma cultura de massas universal: "Enquanto os novos sistemas de comunicação criam acessos para outros povos e nações, e a possibilidade de novas avenidas de desenvolvimento e cooperação política, eles também geram uma consciência da diferença, da diversidade de estilos de vida e orientações de valor. (...) Apesar de que essa consciência possa melhorar o entendimento, ela também pode levar à fragmentação da vida cultural." e) a economia mundial: a economia mundial os sistemas de produção, distribuição e trocas - opera numa escala totalmente desconectada da autoridade formal dos Estados Nacionais.

É clara na literatura a ênfase maior na análise de constrangimentos externos erodindo os Estados Nacionais do que a preocupação com os fatores internos de desagregação. São ainda muito recentes e precárias as interpretações sobre o tribalismo, inclusive não tendo essa terminologia aceitação geral.

\section{DIFERENTES VISÕES SOBRE A CRISE DO ESTADO NACIONAL}

Escolhemos três autores reconhecidos em suas respectivas áreas de competência e que podem representar perspectivas ideológicas e culturais extremamente diferenciadas. Essa diversidade na abordagem do tema pode enriquecer a discussão e propiciar uma visão comparativa interessante.

Peter Drucker (1993), num de seus últimos livros, propõe que a sociedade atual (focalizando exclusivamente os países desenvolvidos) deixou de ser capitalista e, nesse processo de transformações, a Nação-Estado perdeu a antiga soberania. A nova forma de governo adequada à sociedade pós-capitalista implicaria a coexistência de estruturas transnacionais, regionais, a Nação-Estado e as tribos.

Essa convivência de diferentes sistemas políticos não significa a destruição do Estado Nacional, como afirmam os autores que têm a visão radical sobre a globalização. Nessa medida, Drucker (1993, p. XIX) discorda totalmente das observações categóricas de Kenichi Ohmae sobre o fim do Estado: "A Nação-Estado não irá desaparecer. Ela poderá permanecer como órgão político mais poderoso ainda por muito tempo, mas não mais será indispensável. Ela irá dividir cada vez mais seu poder com outros órgãos, outras instituições, outras entidades criadoras de políticas. O que continuará sendo domínio da Nação-Estado? O que será realizado dentro do Estado por organizações autônomas? Como definimos 'supranacional' e 'transnacional'? O que deverá continuar 'separado e local'? Essas perguntas serão questões políticas básicas nas próximas décadas."

Na concepção do autor, vivemos um período de transição intensa na qual as velhas formas sociais e políticas ainda não morreram e as novas já 
estão nascendo, configurando extrema dificuldade na interpretação desses fenômenos. No entanto, a rigor, o livro trata muito pouco das formas de governo adequadas à sociedade pós-capitalista.

A própria terminologia usada, que não nomeia a nova sociedade, mas afirma que a antiga está superada, demonstra a prudência de Drucker na caracterização do novo. O que é muito claro no seu pensamento é a condenação do que ele denomina "megaestado", isto é, a deturpação do Estado liberal num monstrengo que passou a sufocar a sociedade civil.

Drucker faz uma breve análise da evolução do Estado desde sua constituição na Idade Média com a intenção de constatar como, a partir dos fins do século XIX, com a criação do Welfare State e com a ampliação das funções econômicas, fiscais e militares do Estado, essa estrutura fica superdimensionada e passa a obstruir as novas forças do progresso.

Para esse autor, assim como a queda do Muro de Berlim simboliza o fim do socialismo, a coalizão transnacional contra a invasão do Kuwait pelo Iraque em 1990 simboliza o fim do predomínio da Nação-Estado soberana após 400 anos de História como ator principal e freqüentemente o único do cenário político.

São diversas as perspectivas do historiador marxista Eric Hobsbawm, que tem mais simpatias pelo Estado, apesar de concordar com o consultor empresarial de que ele vive séria crise e está em processo acelerado de transformação.

$\mathrm{O}$ autor considera que o início dos anos 70 e, mais precisamente, o primeiro Choque do Petróleo em 1973 marcaram a emergência da primeira crise global, que, no entanto, não foi reconhecida como tal naquele momento. Houve uma depressão cíclica clássica que produziu uma queda de $10 \%$ na produção industrial dos países desenvolvidos e de $13 \%$ no comércio internacional. Com exceção das novas nações industrializadas (NICs), houve severa diminuição do crescimento econômico, aumento das desigualdades entre e intrapaíses, tendo surgido o desemprego estrutural, fruto da revolução tecnológica.

Hoje em dia, é quase unânime na literatura de ciências sociais a localização da primeira crise global no início da década de 70 , que marcaria também a origem do processo de crise do Esta- do. As características mais gerais dessa crise, no pensamento de Hobsbawm (1995, p. 553), não são tão diferentes das apontadas por Drucker: "O Estado-Nação estava sendo erodido de duas formas, de cima e de baixo. Perdia rapidamente poder e função para várias entidades supranacionais, e, na verdade, de forma absoluta, na medida em que a desintegração de grandes Estados e impérios produzia uma multiplicidade de Estados menores, demasiado fracos para defender-se numa era de anarquia internacional. Perdia também, como vimos, seu monopólio de poder efetivo e seus privilégios históricos dentro de suas fronteiras."

No entanto, se a caracterização da crise é semelhante, a concepção sobre a necessidade de interferência do Estado é totalmente diferente. Hobsbawm continua valorizando a intervenção estatal como indispensável para enfrentar as iniqüidades sociais e ambientais do mercado e para garantir algum tipo de redistribuição da renda nacional. De forma convergente com David Held, o historiador inglês também se preocupa com os mecanismos emergentes de coordenação global e com a questão democrática na governança cosmopolita: "Qual seria a natureza e o âmbito das autoridades responsáveis pelas decisões - supranacionais, nacionais, subnacionais e globais, sozinhas ou combinadas? Qual seria a relação delas com as pessoas sobre quem se tomam as decisões?" (Hobsbawm, 1995, p. 555).

A questão subjacente é a da possibilidade da gestão democrática nos organismos emergentes de ordenação política global ou internacional. Como reproduzir os mecanismos de representação política internos aos Estados democráticos para a "governança cosmopolita", na terminologia de Held? 
Assim como se construiu paulatinamente a democracia dentro dos Estados-Nações, envolvendo um processo conflituoso e lento de extensão dos direitos e da participação política dos cidadãos, hoje esse processo começa a ocorrer no plano mundial, envolvendo a busca de ampliação dos direitos e da participação política dos Estados-Nações no planeta Terra.

Ao longo dos séculos XIX e XX, várias nações (principalmente no mundo ocidental) construíram sistemas políticos democráticos, e o século XXI começa com a tarefa de construir um sistema político mundial em que prevaleçam regras democráticas nas relações entre os Estados-Nações.

Com o fim da Guerra Fria e do mundo bipolar dominado por duas potências rivais, o rumo do sistema político internacional parece ser o de um sistema multipolar, com múltiplos pólos de dominação, com a aglutinação das nações em regiões mais amplas e, em terceiro lugar, com a construção de um sistema de relações mais democráticas entre as nações e regiões.

Em outros termos, como legitimar as decisões tomadas no plano internacional? Como seria a democracia na nova ordem mundial? Algumas respostas foram coletadas por Roland Axtmann (1997, p. 143): "Estamos nos movendo para o mundo 'plurilateral' de poder difuso e descentralizado, para um mundo caracterizado por uma variedade de diferentes loci de poder e intersecções e cruzamentos de redes de poder (Cerny, 1993). Para Nederyeen Pieterse (1994:166) esse 'plurilateralismo' pode ser identificado 'no aumento dos modos de organização disponíveis: transnacional, internacional, macro-regional, nacional, micro-regional, municipal e local.' Esses níveis organizacionais são cruzados por redes funcionais de corporações, organizações internacionais, organizações não governamentais e movimentos sociais, assim como profissionais e usuários de computador."

Paul Hirst e Grahame Thompson (1998, p. 295) têm sua própria resposta à questão discutida: "O Estado tem o papel de fonte de legitimidade para transferir poder ou sancionar novos poderes 'acima' e 'abaixo' dele: acima, através de acordos entre os Estados para estabelecer e cumprir as formas de governabilidade internacional; abaixo por meio da ordenação constitucional dentro de seu próprio território da relação de poder e autoridade entre governos centrais, regionais e locais e também os governos privados publicamente reconhecidos pela sociedade civil."

Dessa forma, percebemos como Hobsbawm, ao contrário de Drucker, continua atribuindo enorme importância ao Estado, principalmente por suas funções internas de redistribuição da renda nacional. Por sua vez, os economistas citados também valorizam muito o Estado por suas funções de transferir legitimidade às novas instâncias de autoridade transnacional.

Os pensadores liberais e neoliberais de uma maneira geral tendem a diminuir excessivamente o peso e as funções do Estado, enquanto a postura inversa de defesa radical do estatismo pode redundar em dogmatismo, que ignora as recentes transformações do Estado provocadas pela globalização.

Tentando pensar criticamente a posição dos Estados Unidos como líder de um sistema de Estados Nacionais que hoje sofre profundas transformações, Huntington faz uma análise original e polêmica sobre a recomposição da ordem mundial no limiar do século XXI.

Pensando mais na relação entre os Estados Nacionais do que na crise interna de cada Estado Nacional diante da globalização, o autor traz uma contribuição importante e que vem causando muito debate: "O tema central deste livro é o de que a cultura e as identidades culturais - que, em nível mais amplo, são as identidades das civilizações - estão moldando os padrões de coesão, desintegração e conflito no mundo pósGuerra Fria” (Huntington, 1997, p. 18-9).

$\mathrm{O}$ autor considera que, pela primeira vez na História, a política internacional é simultaneamente multipolar e multicivilizacional, e a globalização não está criando uma civilização universal nem produzindo uma "ocidentalização" das sociedades não-ocidentais.

Huntington contrapõe-se frontalmente às idéias de Francis Fukuyama sobre o "fim da História", que supõe uma universalização cultural do planeta em torno de um conjunto de valores básicos do Ocidente (isto é, a universalização do capitalismo e da democracia).

Não só o Ocidente não está impondo sua cultura às demais civilizações, como estaria perdendo poder e influência no novo equilíbrio entre as nações do mundo: "O equilíbrio de poder entre as civilizações está-se deslocando: a influência relativa do Ocidente está em declínio, com as civilizações asiáticas expandindo seu poderio econômico, militar e político; com o Islã explodindo 
demograficamente, o que gera conseqüências desestabilizadoras para os países islâmicos e seus vizinhos; e com as civilizações não-ocidentais, de forma geral, reafirmando o valor de suas próprias culturas" (Huntington, 1997, p. 19).

As pretensões universalistas do Ocidente, especialmente do líder do mundo ocidental, estariam levando ao conflito com outras civilizações, principalmente com o Islã e a China.

A principal novidade na concepção do autor é a idéia de que o conflito mais importante do mundo contemporâneo não é ideológico ou econômico, não se dá entre ideologias ou nações ricas e pobres, mas entre povos que participam de diferentes culturas, ou melhor, as entidades culturais mais abrangentes que são as civilizações: "Em suma, o mundo pós-Guerra Fria é um mundo de sete ou oito civilizações principais. Os aspectos comuns e as diferenças moldam os interesses, os antagonismos e as associações dos Estados. Os países mais importantes provêm, em sua maioria, de civilizações diferentes. Os conflitos locais que têm maior probabilidade de se transformar em guerras mais amplas são os que existem entre grupos e Estados de civilizações diferentes. Os padrões predominantes de desenvolvimento político e econômico diferem de uma civilização para outra. As questões-chave do cenário internacional envolvem diferenças entre civilizações. O poder está-se deslocando da civilização ocidental que há tanto tempo predomina para civilizações não-ocidentais" (Huntington, 1997, p. 29).

As principais civilizações discerníveis hoje seriam:
a) sínica;
b) japonesa;
c) hindu;
d) islâmica;
e) ocidental;
f) latino-americana;
g) africana (possivelmente).

Dessas civilizações, as que mais desafiam o Ocidente e o antigo equilíbrio mundial de poder são as asiáticas e islâmicas: "A indigenização e a revitalização da religião são fenômenos globais. Entretanto, eles são mais nítidos na afirmação cultural e nos desafios ao Ocidente que têm vindo da Ásia e do Islã. Em ambos estão as civilizações mais dinâmicas do último quarto do século XX (...). Por trás desses desafios, existem causas relacionadas entre si, porém diferentes. A disposição afirmativa da Ásia se funda- menta no crescimento econômico, enquanto que a do Islã provém, em grande parte, da mobilização social e do crescimento populacional" (Huntington, 1997, p. 125).

Diferentemente dos dois outros pensadores analisados, Huntington privilegia a esfera cultural na explicação da dinâmica contemporânea e visualiza um Estado ainda bastante forte e atuante no mundo pós-Guerra Fria.

$\mathrm{O}$ fato de viver e ter trabalhado para o governo do Estado hegemônico (que ele chama de Estado-Núcleo) da civilização ocidental pode ter influenciado a abordagem mais "estatista" dentre os três autores comparados neste artigo. A disciplina a que ele se dedica também colaborou com sua perspectiva menos restritiva sobre o papel do Estado Nacional na política internacional de nossos dias.

No entanto, embora mais "estatista" do que Peter Drucker e mesmo Eric Hobsbawm, Samuel Huntington converge com eles na percepção das limitações que o Estado Nacional vem sofrendo nas últimas três décadas: "Conquanto os Estados continuem sendo os atores principais nos assuntos mundiais, eles também estão sofrendo perdas de soberania, funções e poder. As instituições internacionais agora afirmam seu direito de julgar e de impor limitações ao que os Estados fazem em seus próprios territórios. Em alguns casos, sobretudo na Europa, as instituições internacionais assumiram funções importantes que anteriormente eram desempenhadas pelos Estados, e foram criadas poderosas burocracias que operam diretamente sobre os cidadãos num plano individual. De forma global, vem se verificando uma tendência para que os governos dos Estados também percam poder através da devolução de poder para entidades políticas abaixo do nível de Estado e nos âmbitos regionais, provinciais e locais. Em muitos Estados, inclusive nos do mundo desenvolvido, há movimentos regionais que estão promovendo uma autonomia substancial ou a secessão. Em grau considerável, os governos dos Estados perderam a capacidade de controlar o fluxo de dinheiro que entra em seus países e deles sai, e estão tendo dificuldade cada vez maior para controlar o fluxo de idéias, de tecnologia, de bens e de pessoas. Em resumo, as fronteiras dos Estados se tornaram cada vez mais permeáveis" (Huntington, 1997, p. 36-7).

A comparação entre as perspectivas de Drucker, Hobsbawm e Huntington acerca das transformações recentes do Estado Nacional e 
as contribuições de Held permitem concluir que, assim como os economistas, os que tentam analisar o cenário político contemporâneo também oscilam entre uma visão radical, que considera o Estado em acelerado processo de extinção, e uma visão moderada, que reconhece mudanças importantes impostas pela globalização, mas enxergam enorme poder de resistência nas entidades estatais.

Outra conclusão possível é a de que, seja qual for a postura intelectual acerca do Estado, a questão da possibilidade de uma gestão democrática das novas estruturas políticas internacionalizadas é a grande preocupação de analistas, políticos, administradores e gestores de organismos internacionais: "O Estado deve reagir estruturalmente à globalização. A democratização da democracia antes de mais nada implica descentralização - mas não como um processo unilateral. A globalização cria um forte ímpeto e lógica no sentido da delegação de poder de cima para baixo, mas também uma delegação de poder para cima. Em vez de meramente enfraquecer a autoridade do Estado Nação, esse duplo movimento - um movimento de dupla democratização - é a condição de reafirmação daquela autoridade, uma vez que ele pode tornar o Estado mais reativo às influências que de outro modo o flanqueiam por completo" (Giddens, 1999, p. 82).

Esse importante pensador contemporâneo vem propondo uma renovação da social-democracia, que configuraria um caminho alternativo entre a perspectiva neoliberal e as observações tradicionais da social-democracia européia e do socialismo.

BIBLIOGRAFIA

ARRIGHI, Giovanni. O longo século XX: dinheiro, poder e as origens de nosso tempo. São Paulo/Rio de Janeiro : Unesp/Contraponto, 1996

ARRIGHI, Giovanni. A ilusão do desenvolvimento. São Paulo : Vozes, 1997

AXTMANN, Roland. Liberal democracy into the twenty-first century: globalization, integration and the nation State. Manchester/New York : Manchester University Press, 1997.

BRESSER PEREIRA, Luiz Carlos et al. Reformas econômicas em democracias novas: uma proposta social-democrata. São Paulo : Nobel, 1996.

CARDOSO, Fernando Henrique. Globalização. 0 Estado de S. Paulo, São Paulo, 28 jan. 1996.(Conferência pronunciada em Nova Délhi, India, jan. 1996).

CHESNAIS, François. A mundialização do capital. São Paulo : Xamã, 1996.

DOWBOR, Ladislau. Globalização e tendências institucionais. In: DOWBOR, Ladislau, IANNI, Octávio et al. (Orgs.). Desafios da globalização. Petrópolis : Vozes, 1996.

DRUCKER, Peter. A sociedade pós-capitalista. São Paulo : Pioneira, 1993.

DUPAS, Gilberto. A lógica econômica global e a revisão do Welfare State: a urgência de um novo pacto. São Paulo : Fundação Konrad-Adenauer-Stiftung, 1998. (Pesquisas, n.13, p. 55-6).

FIORI, José Luiz. Em busca do dissenso perdido: ensaios críticos sobre a festejada Crise do Estado. Rio de Janeiro : Insight Editorial,1995.

FIORI, José Luiz. O vôo da coruja: uma leitura não liberal da crise do Estado Desenvolvimentista. Rio de Janeiro : Editora da UERJ, 1995
GIDDENS, Anthony. A terceira via: reflexões sobre 0 impasse político atual e o futuro da social-democracia. Rio de Janeiro : Record, 1999.

HELD, David. Political theory and the modern State: essays on State, power and democracy. Stanford: Stanford University Press, 1989

HELD, David. Democracy and the global order: from the modern State to cosmopolitan governance. Stanford : Stanford University Press, 1995.

HIRST, Paul, THOMPSON, Grahame. Globalização em questão: a economia internacional e as possibilidades de governabilidade. Petrópolis: Vozes, 1998.

HOBSBAWM, Eric. Era dos extremos: o breve século XX (1914-1991). São Paulo : Companhia das Letras, 1995.

HOLLINGSWORTH, J. R., SCHMITTER, P., STREECK, W. Governing capitalist economies: performance and control of economic sectors. New York : Oxford University Press, 1994.

HUNTINGTON, Samuel P. O choque das civilizações e a recomposição da ordem mundial. Rio de Janeiro: Objetiva, 1997.

IANNI, Octávio. Teorias da globalização. Rio de Janeiro : Civilização Brasileira,1995.

IANNI, Octávio et al. (Orgs.). Desafios da globalização. Petrópolis : Vozes, 1998.

KRUGMAN, Paul. Vendendo prosperidade: sensatez e insensatez econômica na Era do Conformismo. Rio de Janeiro : Campus, 1997.

MURRAY, Robin. The internalization of capital and the nation State. New Left Review, n. 67, p. 84-108, May/ June 1971.
NAISBITT, John. Paradoxo global. Rio de Janeiro : Campus, 1994.

OHMAE, Kenichi. O fim do Estado-Nação: a ascensão das economias regionais. Rio de Janeiro : Campus, 1996.

PANITCH, Leo. Globalization and the State. México Universidad Nacional Autónoma de México, 1994.

REINICKE, Wolfgang H. Global public policy: governing without government? Washington DC : Brooking Institution Press, 1998

SADOWSKI, Yahya. The myth of global chaos. Washington DC : Brooking Institution Press, 1998.

SOARES DE LIMA, Maria Regina. Teses equivocadas sobre a ordem mundial pós Guerra Fria. Revista Dados, v. 39, n. 3, p. 393-423, 1996

THUROW, Lester C. O futuro do capitalismo: como as forças econômicas moldam o mundo de amanhã. Rio de Janeiro : Rocco, 1997.

VÁRIOS AUTORES. Inserção na economia global: uma reapreciação. São Paulo : Fundação Konrad-AdenauerStiftung, 1997. (Pesquisas, n. 8).

VÁRIOS AUTORES. A globalização entre o imaginário e a realidade. São Paulo: Fundação KonradAdenauer-Stiftung, 1998. (Pesquisas, n. 13).

WALLERSTEIN, Immanuel. The politics of worldeconomy. the States, the movements and civilizations. Cambridge : Cambridge University Press, 1988.

WORLD BANK. The State in a changing world. World Development Report, 1997.

ZORGBIBE, Charles. Opós-Guerra Fria no mundo. Campinas : Papirus, 1996. 